Glenda Kapstein L. José Luis Santelices E.

Ubicación Av. Angamos 0610, Antofagasta

Mandante Universidad Católica del Norte (Proyecto MECESUP) Cálculo estructural Orlando Rabello G., inseniero U. Chile Climatización, proyecto de energías pasivas Ricardo Zulueta M., físico U. Católica del Norte

Materialidad Estructura de acero, hormisón armado.

Sup. Construida $1.106 \mathrm{~m}^{2}$

Año proyecto 2000

Año Construcción 2001

Fotografía Glenda Kapstein, Eusenio Garcés

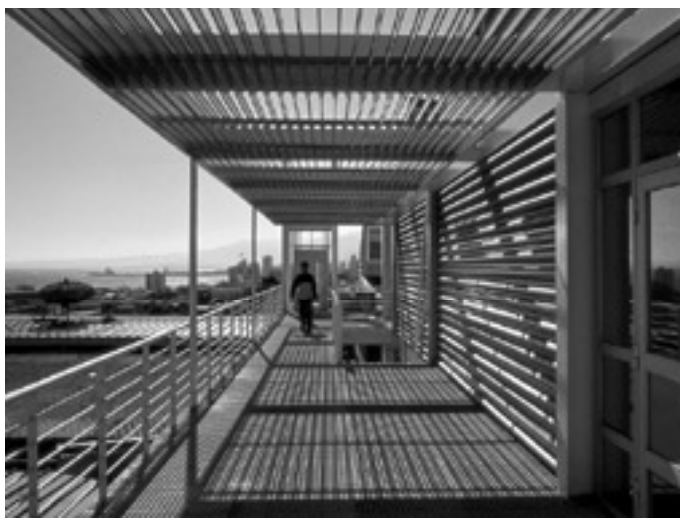

\section{Ampliación Escuela de Arquitectura}

\section{Universidad Católica del Norte}

El proyecto de ampliaci-n de la Escuela de Arquitectura se sito el interior de las dependencias de ella, dentro del campus de la Universidad Cat-lica del Norte, y en ello radica parte de la complejidad delencargo.

El proyecto se compone de tres cuerpos relacionados y pr-ximos, dos de los que corresponden a estructuras existentes sometidasa remodelaciones: 1. El patio oriente ĐclimatizadoĐcuya es tructura metłlicay dimensiones son respetadas.

2. Eltallerde modelos Đen madera y metalĐex-sala de primera-0, cuyo volumen y estructura de muros es respetada engran medida, pero esadecuada alas exigencias delostalleres mencionados.

3. El tercer edipcio corresponde a obra nueva y remplaza una antigua sala de un nivel. En primer piso se sito el taller de primera- 0 , cuya extensi-n natural es el patio climatizado. EI segundo nivel corresponde al taller de computaci-n y el tercer nivel a dos talleres de arquitectura. Se puede decir que este volumen, por su envergadura y posici-n, preside el conjunto.

La geometr'a, las medidas y los materiales son recogidos desde la modulaci-nde las dependencias de la escuela: entramado simple de estructura metłlica que respeta la longitud del acero ( $6 \mathrm{mts}$.) Las medidas entre pilares son 3 y $6 \mathrm{mts}$. para producir la continuidad con la estructura existente.

Por ser la m‡s importante de las ampliaciones realizadas hasta ahora implicaba para los arquitectos un desaf'o en plantear las partes de futuras remodelaciones y ampliaciones de la escuela. De aqu' que el proyecto plantea dos asuntos de importancia: el sistema de conexiones o pasillo por una parte y el uso de los materiales. El sistema de circulaciones se preocupa de integrar esta obra nueva a la vida del lugar a travŽs de pasillos, puertas, escaleras ymontacarga, dando las pautas para futuras ampliaciones.

Ambientalmente, el nuevo edipcio se preocupa de la ventilaci-n natural cruzada a travŽs de planchas Luxal-n perforadas y celos'as en primernivel. La iluminaci-matural de los talleres, patio oriente y taller de modelos se produce cenitalmente.

La estructura es realizada en acero en su totalidad, y consiste en un entramado de marcos arriostrados conlosas colaborantes. Los muros son de planchas softwave de Hunter Douglas con hormig $-\mathrm{n}$ liviano al interior, que los arquitectos autores del proyecto llamamos muros colaborantes. Los muros son continuos y se interrumpen para dejar la plancha exterior perforada a la vista.

En la parte superior, las pasarelas-pasillo se resuelven en tecnomalla industrial de modo que la luz y ventilaci-nse dan en forma natural a travŽs de los pisos, colaborando con el clima interior de los talleres.

Glenda Kapstein L.

Arquitecta U Chile-Valpara'so Master en Arquitectura P.U.C.

José Luis Santelices E

Arquitecto U. de Chile-Santiago Master en Arquitectura Rice University

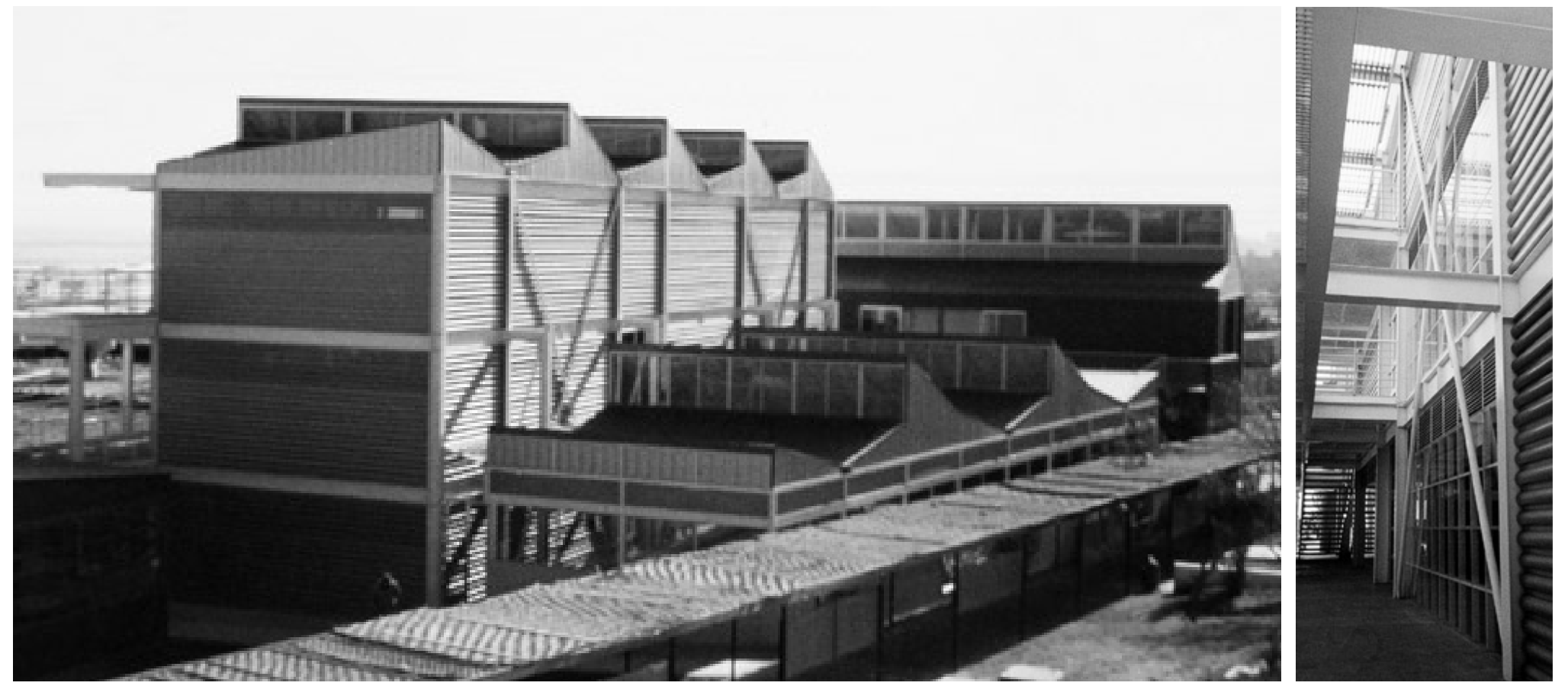

